\title{
The relationship between health-related fitness and quality of life in postmenopausal women from Southern Taiwan
}

\author{
This article was published in the following Dove Press journal: \\ Clinical Interventions in Aging \\ 16 September 2014 \\ Number of times this article has been viewed
}

\author{
Wei-Hsiu Hsu'-3 \\ Chi-lung Chen ${ }^{2}$ \\ Liang Tseng Kuo ${ }^{2}$ \\ Chun-Hao Fan' \\ Mel S Lee ${ }^{2}$ \\ Robert Wen-Wei Hsu²
}

'Sports Medicine Center, Chang Gung Memorial Hospital at Chia Yi, Chia Yi, Taiwan; ${ }^{2}$ Division of Sports Medicine, Department of Orthopedic Surgery, Chang Gung Memorial Hospital at Chia Yi, Chia Yi, Taiwan; ${ }^{3}$ Department of Medicine, Chang Gung University, Tao Yuan, Taiwan
Correspondence: Wei-Hsiu Hsu Department of Orthopedic Surgery, Chang Gung Memorial Hospital at Chia Yi, No 6 West Section, Chia Pu Road, Puzih, Chia Yi Hsien 613, Taiwan

Tel +886 $5362 \quad 1000$ ext 2855

Fax +88653623002

Email 7572@cgmh.org.tw
Background: Health-related fitness has been reported to be associated with improved quality of life (QoL) in the elderly. Health-related fitness is comprised of several dimensions that could be enhanced by specific training regimens. It has remained unclear how various dimensions of health-related fitness interact with QoL in postmenopausal women.

Objective: The purpose of the current study was to investigate the relationship between the dimensions of health-related fitness and QoL in elderly women.

Methods: A cohort of 408 postmenopausal women in a rural area of Taiwan was prospectively collected. Dimensions of health-related fitness, consisting of muscular strength, balance, cardiorespiratory endurance, flexibility, muscle endurance, and agility, were assessed. QoL was determined using the Short Form Health Survey (SF-36). Differences between age groups (stratified by decades) were calculated using a one-way analysis of variance (ANOVA) and multiple comparisons using a Scheffé test. A Spearman's correlation analysis was performed to examine differences between QoL and each dimension of fitness. Multiple linear regression with forced-entry procedure was performed to evaluate the effects of health-related fitness. A $P$-value of $<0.05$ was considered statistically significant.

Results: Age-related decreases in health-related fitness were shown for sit-ups, back strength, grip strength, side steps, trunk extension, and agility $(P<0.05)$. An age-related decrease in QoL, specifically in physical functioning, role limitation due to physical problems, and physical component score, was also demonstrated $(P<0.05)$. Multiple linear regression analyses demonstrated that back strength significantly contributed to the physical component of QoL (adjusted beta of $0.268[P<0.05])$.

Conclusion: Back strength was positively correlated with the physical component of QoL among the examined dimensions of health-related fitness. Health-related fitness, as well as the physical component of QoL, declined with increasing age.

Keywords: postmenopausal women, health related fitness, back strength, quality of life

\section{Introduction}

Aging is often associated with functional limitations and disability. The aging process is typically characterized by a loss of muscular strength, reduction in joint mobility, reduction in cardiovascular capacity, and a decline in cognitive capacity. ${ }^{1}$ These physiological changes become more pronounced in postmenopausal women due to the development of osteoporosis and sarcopenia. ${ }^{2-4}$ These age-related declines can be assessed using health-related measures of fitness. ${ }^{5,6}$ Health-related fitness comprises several dimensions, including body composition, cardiorespiratory endurance, muscular strength, muscle endurance, agility, balance, and flexibility. ${ }^{5,7}$ Each dimension can be enhanced by using specific training regimens. ${ }^{8-13}$ 
Health-related quality of life (QoL) has been used to assess the overall status of patients; QoL has also been shown to be negatively correlated with age. ${ }^{14,15}$ Specifically, scores on physical functioning, physical role limitation, general health, and social functioning have been shown to decrease significantly with age in postmenopausal women. ${ }^{16}$ An inferior self-perceived QoL is associated with poor exercise adherence, which has been proposed to further jeopardize health-related fitness. ${ }^{17}$ Regular physical activity and/or exercise training programs are beneficial in minimizing the physiological alterations that occur with aging and contribute to improvements in overall health and well-being. ${ }^{18,19}$ It remains unclear how the various dimensions of health-related fitness are associated with QoL in postmenopausal women. Understanding which dimensions of health-related fitness impact QoL in the elderly could have significant implications in the prescription of exercise in this population, since different dimensions of health-related fitness can be enhanced using specific exercise training programs. ${ }^{8-13,19-23}$ The purpose of the current study was to investigate the relationship between different dimensions of health-related fitness and QoL in elderly postmenopausal women from Taiwan. We hypothesized an age-related decrease in health-related fitness and that reduced health-related fitness would be predictive of QoL in postmenopausal women.

\section{Materials and methods Participants}

A total of 408 postmenopausal women from Chia Yi area and Yunlin County of Taiwan were enrolled in the current investigation between August 2010 and December 2012. Postmenopausal women were defined as having had no menstruation in the previous 12 months..$^{24,25}$ The inclusion criteria of this study were: 1) postmenopausal women who were 2) healthy and 3) physically independent. The exclusion criteria were symptomatic cardiorespiratory disease, cognitive impairment or progressive and debilitating conditions, recent bone fractures, or any other medical contraindications to performing the fitness assessment.

Participants were divided into three groups stratified by age (group A: 50.0-59.9 years; group B: 60.0-69.9 years; group $\mathrm{C}:>70.0$ years). The following anthropometric parameters were measured: height, body weight, health-related fitness, and QoL. All participants were Taiwanese from the Southern region of the country. This study was approved by the institutional review board of Chang Gung Foundation (IRB102-2419C), Tao Yuan, Taiwan.

\section{Fitness assessment}

Fitness of all subjects was evaluated using the HELMAS Physical Fitness Management System (O2RUN, CO., LTD., Seoul, Korea) at the Sports Medicine Center, Chang Gung Memorial Hospital at Chia Yi. Several dimensions of healthrelated fitness were evaluated, including muscular strength (grip strength and back strength); balance (closed-eye foot balance); cardiorespiratory endurance (step test); flexibility (sitting trunk flexion and trunk extension); muscle endurance (sit-ups); and agility (reaction time and side steps). ${ }^{26-29}$

\section{Muscular strength}

Grip strength and back strength were evaluated using a (dominant) hand and back dynamometer (HELMAS NH-3000D and NH-3000E). The better of two measurements was recorded.

\section{Cardiorespiratory endurance}

Subjects performed a 3-minute step test to evaluate cardiorespiratory endurance. Subjects were asked to step at a pace of 24 cycles per minute (metronome $=96$ beats per minute) using a $35 \mathrm{~cm}$ step box. After 3 minutes of stepping, subjects immediately sat down, and heart rate was recorded from 1 to 1.5 minutes posttest, 2 to 2.5 minutes posttest, and 3 to 3.5 minutes posttest (ACC-750B; Accuratus, New Taipei City, Taiwan). The results were recorded as time until exhaustion (seconds) and total heartbeats; these data were then plotted into a fitness index equation (FIE):

$$
F I E=\frac{\text { Time until exhaustion } \times 100}{\text { Total heartbeats counted } \times 2} .
$$

\section{Balance}

To assess balance, subjects closed their eyes and stood on their dominant leg on a balance-measuring instrument (HELMAS NH-3000H). The better time of two tests was recorded.

\section{Flexibility}

For sitting trunk flexion, subjects sat on a flexibility measuring instrument (HELMAS NH-3000G) with their heels positioned at the edge of the device. Patients then bent forward at the waist with their hands outstretched in front of them to push the measuring instrument as far as possible past their feet. The better of two tests was recorded $(\mathrm{cm})$.

Trunk extension was evaluated with the patient in a prone position on a flexibility-measuring instrument (HELMAS NH-3000R). The better of two tests was recorded $(\mathrm{cm})$. 


\section{Muscular endurance}

The number of sit-ups performed in a 30 -second period was recorded for subjects lying on a sit-up board with their knees bent at right angles and both hands positioned behind their necks (HELMAS NH-3000N). Subjects were encouraged to use only their upper body during each repetition.

\section{Agility}

A subject's reaction time was measured with both their feet on a measuring instrument (HELMAS NH-3000I). Subjects were asked to jump vertically using both feet in response to a visual cue. The better of two tests was recorded (ms). The side step was measured using a labeled exercise board (HELMAS NH-3000J). The board was labeled at midline, with a parallel line $100 \mathrm{~cm}$ away (peripheral line) on either side of the midline. In alternating fashion, subjects were asked to perform lateral side steps to the left and right, touching the peripheral line with their feet. The total number of steps over the right or left peripheral line in 20 seconds was recorded.

\section{QoL}

QoL was assessed using the Short Form Health Survey (SF-36, Taiwan version). ${ }^{30}$ The SF-36 questionnaire is a multipurpose and short-form health survey, which is commonly used to evaluate patients' QoL in clinical practice. A total of eight domains were evaluated in this questionnaire, including physical functioning, role limitation due to physical problems, bodily pain, general health, vitality, social functioning, role limitation due to emotional problem, and mental health. Additionally, the eight health domains can be used to provide a physical component summary and a mental component summary score.

\section{Statistical analysis}

All data analyses were performed using the Statistical Package for the Social Sciences for Windows (v 17.0;
SPSS Inc., Chicago, IL, USA). All continuous data were presented as the mean \pm standard deviation. Differences between groups based on age were calculated using a one-way analysis of variance (ANOVA) and multiple comparisons using a Scheffé test. A $P$-value of $<0.05$ was considered statistically significant. Trends and associations between variables were evaluated further using Spearman's analysis of correlation. Multiple linear regressions with forced-entry procedure were performed to determine the predictors for QoL.

\section{Results}

A total of 408 subjects were enrolled in this study. The mean age of enrolled subjects was 64 years (range: 50-89 years). Mean subject body mass index was $25 \mathrm{~kg} / \mathrm{m}^{2}$ (range: 16-38). An age-related decrease in body height $(P<0.05)$ was observed (Table 1). With aging, dimensions of healthrelated fitness were reduced, including sit-ups, back and grip strength, side-step assessment, trunk extension, and agility $(P<0.05)$ (Table 2). No differences were observed in the closed-eye balance test, sitting trunk flexion assessment, and step test between age-ranked groups. In QoL assessment, physical functioning, role limitation due to physical problems, and physical component score were also decreased in aged groups $(P<0.05)$ (Table 3$)$.

In order to determine the relationship between each dimension of health-related fitness and QoL (physical and mental component scores), Pearson's correlation analysis was performed (Table 4). A positive correlation between the physical component score of QoL and fitness was observed, specifically for sit-ups (correlation coefficient $=0.177$ ), back strength (0.334), grip strength $(0.286)$, side steps $(0.255)$, sitting trunk flexion (0.145), and trunk extension (0.297) $(P<0.01$ for all). A negative correlation between the mental component score of QoL and fitness was observed for closed-eye foot balance $(r=-0.100, P<0.01)$. The different domains of fitness were also shown to be interrelated, specifically back strength correlated with grip strength,

Table I Demographic data of participants

\begin{tabular}{|c|c|c|c|c|c|}
\hline & $\begin{array}{l}\text { All } \\
(N=408)\end{array}$ & $\begin{array}{l}50-59 \text { years } \\
(n=\mid 40)\end{array}$ & $\begin{array}{l}60-69 \text { years } \\
(n=162)\end{array}$ & $\begin{array}{l}>70 \text { years } \\
(n=106)\end{array}$ & Scheffé \\
\hline & Mean \pm SD & Mean \pm SD & Mean \pm SD & Mean \pm SD & \\
\hline Age (years) & $64 \pm 9$ & $55 \pm 3$ & $65 \pm 3$ & $75 \pm 4$ & $\mathrm{~A}<\mathrm{B}<\mathrm{C}$ \\
\hline Height (cm) & $155 \pm 5$ & $156 \pm 5$ & $155 \pm 5$ & $153 \pm 5$ & $A>B>C$ \\
\hline Weight (kg) & $59 \pm 9$ & $59 \pm 8$ & $60 \pm 9$ & $58 \pm 8$ & \\
\hline BMI $\left(\mathrm{kg} / \mathrm{m}^{2}\right)$ & $25 \pm 3$ & $24 \pm 3$ & $25 \pm 4$ & $25 \pm 3$ & \\
\hline
\end{tabular}

Note: A: $50-59$ years; B: $60-69$ years; C: $>70$ years.

Abbreviations: BMI, body mass index; SD, standard deviation. 
Table 2 Participant health-related fitness

\begin{tabular}{|c|c|c|c|c|c|}
\hline \multirow[t]{2}{*}{ Fitness test } & \multirow{2}{*}{$\begin{array}{l}\text { All } \\
(n=408) \\
\text { Mean } \pm \text { SD }\end{array}$} & \multirow{2}{*}{$\begin{array}{l}50-59 \text { years } \\
(n=I 40) \\
\text { Mean } \pm S D\end{array}$} & \multirow{2}{*}{$\begin{array}{l}60-69 \text { years } \\
(n=162) \\
\text { Mean } \pm \text { SD }\end{array}$} & \multirow{2}{*}{$\begin{array}{l}>70 \text { years } \\
(n=106) \\
\text { Mean } \pm \text { SD }\end{array}$} & \multirow[t]{2}{*}{ Scheffé } \\
\hline & & & & & \\
\hline Sit-ups (number performed) & $2 \pm 4$ & $3 \pm 4$ & $2 \pm 4$ & $\mathrm{I} \pm 2$ & $A, B>C$ \\
\hline Back strength $(\mathrm{kg})$ & $47 \pm 22$ & $52 \pm 22$ & $49 \pm 23$ & $36 \pm 18$ & $A, B>C$ \\
\hline Grip strength (kg) & $20 \pm 6$ & $22 \pm 6$ & $20 \pm 6$ & $17 \pm 7$ & $A, B>C$ \\
\hline Side steps (number performed) & $14 \pm 6$ & $17 \pm 6$ & $13 \pm 6$ & $10 \pm 5$ & $A>B>C$ \\
\hline Reaction time (ms) & $604 \pm 345$ & $535 \pm 413$ & $606 \pm 273$ & $703 \pm 323$ & $C>A$ \\
\hline Closed-eye foot balance (s) & $7 \pm 7$ & $9 \pm 8$ & $7 \pm 7$ & $5 \pm 6$ & $\mathrm{~A}>\mathrm{B}, \mathrm{C}$ \\
\hline Sitting trunk flexion $(\mathrm{cm})$ & $6 \pm 11$ & $6 \pm 11$ & $7 \pm 10$ & $4 \pm 12$ & \\
\hline Trunk extension $(\mathrm{cm})$ & $2 I \pm I I$ & $26 \pm 11$ & $21 \pm 10$ & $13 \pm 10$ & $A>B>C$ \\
\hline Step test (score) & $64 \pm I I$ & $63 \pm 10$ & $65 \pm 12$ & $62 \pm 11$ & \\
\hline
\end{tabular}

Note: A: $50-59$ years; B: $60-69$ years; C: $>70$ years.

Abbreviation: SD, standard deviation.

side steps, and trunk extension $(r=0.603,0.506$, and 0.490 , respectively, $P<0.01$ ).

To identify potential predictive factors for the physical and mental components of QoL, multiple linear regression analyses were performed using forced-entry procedure, adjusted for age. All dimensions of health-related fitness were selected and represented as independent factors in the multiple linear regression analysis. The regression model was checked for normality of residuals and displayed a normal distribution. Results demonstrated that back strength significantly contributed to the physical component of QoL with an adjusted beta of $0.268(P<0.05)$ (Table 5).

\section{Discussion}

The most important finding of the current study was that back strength was the best predictor of the physical component of QoL among the dimensions of health-related fitness in postmenopausal women (Figure 1). The current results are consistent with previous reports describing back strength as an important contributing factor for improved QoL in women with postmenopausal osteoporosis ${ }^{15}$ as well as the pivotal role of back strength in the improvement of QoL in the elderly. ${ }^{31-33} \mathrm{An}$ increase in back strength resulting from exercise could improve QoL in postmenopausal women. ${ }^{31}$ Therefore, improved back strength is an important target for exercise training in an effort to enhance the physical components of QoL. Increased back strength, and any associated improvement in the physical component of QoL, may encourage adherence to prescribed exercise training regimens. The remaining dimensions of health-related fitness could be improved to achieve postural alignment, dynamic balance, functional mobility, and back extensor strength, which are associated with mobility limitations and an increased risk of falling in older adults. ${ }^{34-36}$ In the

Table 3 Participant quality of life (SF-36)

\begin{tabular}{|c|c|c|c|c|c|}
\hline \multirow[t]{2}{*}{ SF-36 (score) } & \multirow{2}{*}{$\begin{array}{l}\begin{array}{l}\text { All } \\
(n=408)\end{array} \\
\text { Mean } \pm \text { SD }\end{array}$} & \multirow{2}{*}{$\begin{array}{l}50-59 \text { years } \\
(n=I 40) \\
\text { Mean } \pm \text { SD }\end{array}$} & \multirow{2}{*}{$\begin{array}{l}60-69 \text { years } \\
(n=162) \\
\text { Mean } \pm \text { SD }\end{array}$} & \multirow{2}{*}{$\begin{array}{l}>70 \text { years } \\
(n=106) \\
\text { Mean } \pm \text { SD }\end{array}$} & \multirow[t]{2}{*}{ Scheffé } \\
\hline & & & & & \\
\hline PF & $79 \pm 19$ & $83 \pm 18$ & $77 \pm 18$ & $75 \pm 22$ & $\mathrm{~A}>\mathrm{B}, \mathrm{C}$ \\
\hline RP & $58 \pm 44$ & $63 \pm 41$ & $62 \pm 43$ & $45 \pm 46$ & $A, B>C$ \\
\hline BP & $70 \pm 23$ & $7 I \pm 23$ & $7 I \pm 23$ & $69 \pm 21$ & \\
\hline $\mathrm{GH}$ & $56 \pm 20$ & $57 \pm 20$ & $55 \pm 20$ & $58 \pm 19$ & \\
\hline VT & $60 \pm 14$ & $58 \pm 13$ & $60 \pm 15$ & $62 \pm 12$ & \\
\hline SF & $87 \pm 17$ & $85 \pm 16$ & $87 \pm 19$ & $88 \pm 16$ & \\
\hline RE & $71 \pm 42$ & $74 \pm 39$ & $69 \pm 42$ & $70 \pm 44$ & \\
\hline $\mathrm{MH}$ & $69 \pm 17$ & $68 \pm 18$ & $69 \pm 18$ & $73 \pm 16$ & \\
\hline PCS & $47 \pm 9$ & $49 \pm 9$ & $47 \pm 9$ & $45 \pm 9$ & $A>C$ \\
\hline MCS & $49 \pm 10$ & $48 \pm 9$ & $48 \pm 10$ & $5 I \pm 10$ & \\
\hline
\end{tabular}

Note: A: $50-59$ years; B: $60-69$ years; C: $>70$ years.

Abbreviations: BP, bodily pain; GH, general health; MCS, mental component summary; MH, mental health; PCS, physical component summary; PF, physical functioning; RE, role limitation due to emotional problem; RP, role limitation due to physical problems; SD, standard deviation; SF, social functioning; SF-36, Short Form Health Survey; VT, vitality. 


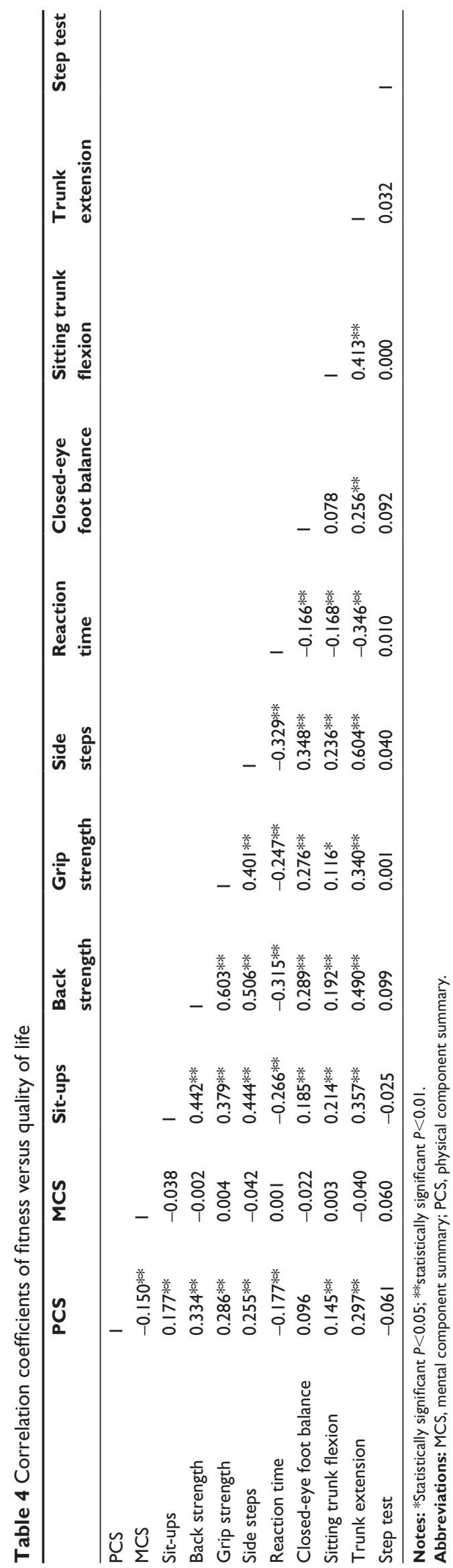

present study, we also demonstrated that back strength was positively correlated with grip strength, and that these domains probably share a common feature reflecting muscle strength. Trunk strength and endurance are important factors in the rehabilitation of ambulatory elderly patients. ${ }^{32}$ Recently, exercises specific for the abdominal core muscles have received attention for injury prevention, relief of lower back pain, and enhancing QoL. ${ }^{37,38}$ The current findings suggest that further strategies for improving muscle strength and endurance are needed.

In the current study, health-related fitness and the physical component of QoL declined with increasing age, while the mental component of QoL increased with aging. Furthermore, participants aged 50-59 years had greater fitness compared with their $\geq 60$-year-old counterparts, consistent with previous reports wherein an age-related decline was observed in health-related fitness, including in muscular strength, flexibility, agility, and endurance. ${ }^{5,37}$ Age-related decreases in health-related fitness are important, since the resulting postural misalignment, balance deficits, and strength/power loss are associated with impaired functional mobility and an increased risk of falling..$^{32,34,38}$ Therefore, muscle strengthening intervention may provide improved QoL and thus motivate the elderly to continue exercises that could minimize the age-related decline of fitness. Regarding the assessment of QoL, the current results are consistent with previous reports of the physical component of QoL being negatively correlated with age, ${ }^{16,33}$ whereas the association between the mental component of QoL and age remains controversial. ${ }^{16,33,39}$ Some studies have indicated that the mental component of QoL is not correlated with age, ${ }^{16,33}$ however, in subjects from rural Taiwan, we found an increase in the mental component of QoL with aging. These findings may be partially explained by reduced physical health and improved mental health among women living in rural areas compared with those women from an urban setting. ${ }^{39}$

Although an appropriate sample size and the homogeneity of subjects provided some strength in the present study, it was still limited by its cross-sectional design in terms of selection bias, ie, only associations were shown, not causality or temporal relationships. Further, this study was performed in a rural area in Southern Taiwan, where most participants performed agricultural work and had strong community support, factors that contribute to a lesser impact of hypokinetics and loneliness, which may result in a reduction in the mental component of QoL. Further studies should be performed to validate the current findings, with 
Table 5 Multiple regression analysis of quality of life

\begin{tabular}{|c|c|c|c|c|c|c|c|c|}
\hline \multirow{2}{*}{$\begin{array}{l}\text { Dependent } \\
\text { variable }\end{array}$} & & \multicolumn{2}{|c|}{ Unstandardized coefficients } & \multirow{2}{*}{$\begin{array}{l}\text { Standardized coefficients } \\
\beta\end{array}$} & \multirow[b]{2}{*}{$R^{2}$} & \multirow[b]{2}{*}{$\Delta R^{2}$} & \multicolumn{2}{|l|}{$95 \% \mathrm{Cl}$} \\
\hline & & B & Standard error & & & & Lower & Upper \\
\hline \multirow[t]{10}{*}{ PCS } & Intercept & 42.155 & 3.428 & & 0.103 & 0.103 & 35.411 & 48.899 \\
\hline & Sit-ups & -0.034 & 0.138 & -0.016 & & & -0.305 & 0.236 \\
\hline & Back strength & 0.078 & 0.028 & $0.268^{*}$ & & & 0.023 & 0.134 \\
\hline & Grip strength & 0.124 & 0.095 & 0.088 & & & -0.063 & 0.310 \\
\hline & Side steps & 0.082 & 0.095 & 0.061 & & & -0.104 & 0.268 \\
\hline & Reaction time & 0.002 & 0.002 & 0.056 & & & -0.002 & 0.006 \\
\hline & Foot balance & -0.027 & 0.061 & -0.025 & & & -0.146 & 0.092 \\
\hline & Sitting trunk flexion & 0.039 & 0.047 & 0.047 & & & -0.054 & 0.131 \\
\hline & Trunk extension & 0.060 & 0.055 & 0.075 & & & -0.047 & 0.168 \\
\hline & Step test & -0.064 & 0.039 & -0.087 & & & -0.142 & 0.013 \\
\hline \multirow[t]{10}{*}{ MCS } & Intercept & 40.458 & 4.170 & & 0.015 & 0.015 & 32.254 & 48.663 \\
\hline & Sit-ups & -0.117 & 0.168 & -0.047 & & & -0.447 & 0.212 \\
\hline & Back strength & 0.001 & 0.034 & 0.001 & & & -0.067 & 0.068 \\
\hline & Grip strength & 0.155 & 0.115 & 0.095 & & & -0.072 & 0.382 \\
\hline & Side steps & 0.006 & 0.115 & 0.004 & & & -0.221 & 0.233 \\
\hline & Reaction time & 0.002 & 0.002 & 0.045 & & & -0.003 & 0.006 \\
\hline & Foot balance & -0.036 & 0.074 & -0.029 & & & -0.181 & 0.109 \\
\hline & Sitting trunk flexion & 0.012 & 0.057 & 0.013 & & & -0.100 & 0.125 \\
\hline & Trunk extension & 0.032 & 0.066 & 0.034 & & & -0.099 & 0.162 \\
\hline & Step test & 0.054 & 0.048 & 0.063 & & & -0.040 & 0.148 \\
\hline
\end{tabular}

Note: $* p<0.05$.

Abbreviations: $\mathrm{Cl}$, confidence interval; $\mathrm{MCS}$, mental component summary; PCS, physical component summary.

interventional studies performed to test the hypothesis put forward by the current study.

\section{Conclusion}

Back strength was an important contributor for the physical component of QoL among the dimensions of health-related fitness in postmenopausal women. Further investigation is warranted to delineate the effect of exercise intervention

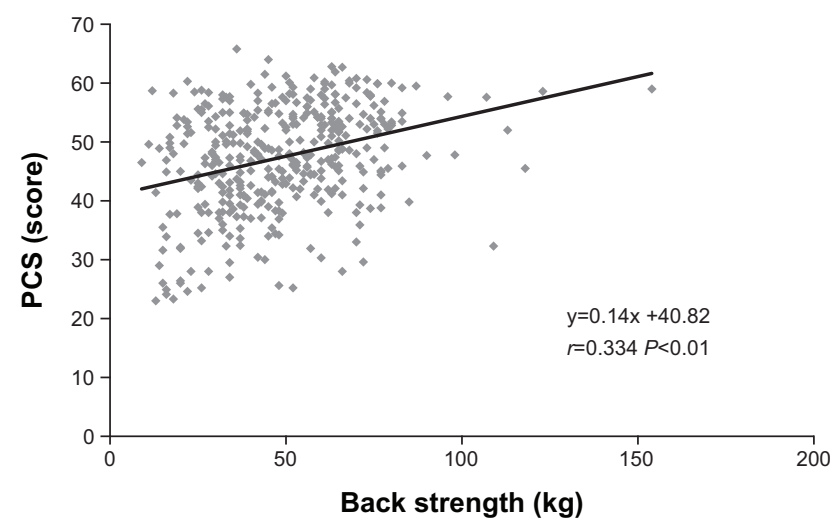

Figure I Scatterplots showing the correlation between PCS of quality of life versus back strength.

Note: An increase in back strength significantly contributed to an increase in the PCS of quality of life.

Abbreviation: PCS, physical component summary. through targeted activities for back strength, such as Pilates, yoga, or core muscle strengthening exercises.

\section{Acknowledgments}

This study was approved by the institutional review board of Chang Gung Foundation (IRB102-2419C). This study was funded by Chang Gung Memorial Hospital Grant CMRPG 690103 and Chang Gung Memorial Hospital Grant CMRPG 690102. The authors are grateful for the financial support.

\section{Disclosure}

The authors report no conflicts of interest in this work.

\section{References}

1. Watsford ML, Murphy AJ, Pine MJ. The effects of ageing on respiratory muscle function and performance in older adults. J Sci Med Sport. 2007; 10:36-44.

2. Lee JY, Lee DC. Muscle strength and quality are associated with severity of menopausal symptoms in peri- and post-menopausal women. Maturitas. 2013;76:88-94.

3. Messier V, Rabasa-Lhoret R, Barbat-Artigas S, Elisha B, Karelis AD, Aubertin-Leheudre M. Menopause and sarcopenia: a potential role for sex hormones. Maturitas. 2011;68:331-336.

4. Frisoli A Jr, Chaves PH, Ingham SJ, Fried LP. Severe osteopenia and osteoporosis, sarcopenia, and frailty status in community-dwelling older women: results from the Women's Health and Aging Study (WHAS) II. Bone. 2011;48:952-957. 
5. Milanović Z, Pantelić S, Trajković N, Sporiš G, Kostić R, James N. Age-related decrease in physical activity and functional fitness among elderly men and women. Clin Interv Aging. 2013;8:549-556.

6. Takata Y, Ansai T, Soh I, et al. Quality of life and physical fitness in an 85-year-old population. Arch Gerontol Geriatr. 2010;50:272-276.

7. Takata Y, Ansai T, Soh I, et al. Physical fitness and 6.5-year mortality in an 85-year-old community-dwelling population. Arch Gerontol Geriatr. 2012;54:28-33.

8. Binder EF, Schechtman KB, Ehsani AA, et al. Effects of exercise training on frailty in community-dwelling older adults: results of a randomized, controlled trial. J Am Geriatr Soc. 2002;50: 1921-1928.

9. Binder EF, Yarasheski KE, Steger-May K, et al. Effects of progressive resistance training on body composition in frail older adults: results of a randomized, controlled trial. J Gerontol A Biol Sci Med Sci. 2005;60: $1425-1431$.

10. Ciolac EG, Garcez-Leme LE, Greve JM. Resistance exercise intensity progression in older men. Int J Sports Med. 2010;31:433-438.

11. Evans WJ. Effects of exercise on body composition and functional capacity of the elderly. J Gerontol A Biol Sci Med Sci. 1995;50:147-150.

12. Kohrt WM, Malley MT, Coggan AR, et al. Effects of gender, age, and fitness level on response of VO2max to training in 60-71 yr olds. $J$ Appl Physiol (1985). 1991;71:2004-2011.

13. Paoli A, Pacelli F, Bargossi AM, et al. Effects of three distinct protocols of fitness training on body composition, strength and blood lactate. J Sports Med Phys Fitness. 2010;50:43-51.

14. Schroll M, Schlettwein D, van Staveren W, Schlienger JL. Health related quality of life and physical performance. SENECA 1999. J Nutr Health Aging. 2010;6:15-19.

15. Miyakoshi N, Hongo M, Maekawa S, Ishikawa Y, Shimada Y, Itoi E. Back extensor strength and lumbar spinal mobility are predictors of quality of life in patients with postmenopausal osteoporosis. Osteoporos Int. 2007;18:1397-1403.

16. Budakoğlu II, Ozcan C, Eroğlu D, Yanik F. Quality of life and postmenopausal symptoms among women in a rural district of the capital city of Turkey. Gynecol Endocrinol. 2007;23:404-409.

17. Laforge RG, Rossi JS, Prochaska JO, Velicer WF, Levesque DA, McHorney CA. Stage of regular exercise and health-related quality of life. Prev Med. 1999;28:349-360.

18. American College of Sports Medicine; Chodzko-Zajko WJ, Proctor DN, et al. American College of Sports Medicine position stand. Exercise and physical activity for older adults. Med Sci Sports Exerc. 2009;41: $1510-1530$.

19. Stewart KJ, Turner KL, Bacher AC, et al. Are fitness, activity, and fatness associated with health-related quality of life and mood in older persons? J Cardiopulm Rehabil. 2003;23:115-121.

20. Ciolac EG, Brech GC, Greve JM. Age does not affect exercise intensity progression among women. $J$ Strength Cond Res. 2010;24: 3023-3031.

21. Baker MK, Kennedy DJ, Bohle PL, et al. Efficacy and feasibility of a novel tri-modal robust exercise prescription in a retirement community: a randomized, controlled trial. J Am Geriatr Soc. 2007;55:1-10.
22. Nelson ME, Fiatarone MA, Morganti CM, Trice I, Greenberg RA, Evans WJ. Effects of high-intensity strength training on multiple risk factors for osteoporotic fractures. A randomized controlled trial. JAMA. 1994;272:1909-1914.

23. Chan DC, Tsou HH, Yang RS, et al. A pilot randomized controlled trial to improve geriatric frailty. BMC Geriatr. 2012;12:58.

24. Vandenakker BC, Glass DD. Menopause and aging with disability. Phys Med Rehabil Clin N Am. 2001;12(1):133-151.

25. Croarkin E. Osteopenia: implications for physical therapists managing patients of all ages. PT: Magazine of Physical Therapy. 2001;9:80.

26. Kell RT, Bell G, Quinney A. Musculoskeletal fitness, health outcomes and quality of life. Sports Med. 2001;31:863-873.

27. American College of Sports Medicine. ACSM's Guidelines for Exercise Testing and Prescription. Philadelphia: Lippincott, Williams \& Wilkins; 1995.

28. AAHPERD. Technical Manual: Health-Related Physical Fitness. Washington, DC: American Association for Active Lifestyles \& Fitness; 1984.

29. ICSPFT. Fitness, Health, and Work Capacity: International Standards for Assessment. New York: Macmillan; 1974.

30. Tsai SY, Chi LY, Lee LS, Chou P. Health-related quality of life among urban, rural, and island community elderly in Taiwan. J Formos Med Assoc. 2004;103:196-204.

31. Hongo M, Itoi E, Sinaki M, et al. Effect of low-intensity back exercise on quality of life and back extensor strength in patients with osteoporosis: a randomized controlled trial. Osteoporos Int. 2007;18:1389-1395.

32. Suri P, Kiely DK, Leveille SG, Frontera WR, Bean JF. Trunk muscle attributes are associated with balance and mobility in older adults: a pilot study. PM R. 2009;1:916-924.

33. Imagama $\mathrm{S}$, Matsuyama $\mathrm{Y}$, Hasegawa $\mathrm{Y}$, et al. Back muscle strength and spinal mobility are predictors of quality of life in middle-aged and elderly males. Eur Spine J. 2011;20:954-961.

34. Kasukawa Y, Miyakoshi N, Hongo M, et al. Relationships between falls, spinal curvature, spinal mobility and back extensor strength in elderly people. J Bone Miner Metab. 2010;28:82-87.

35. Katzman WB, Vittinghoff E, Kado DM. Age-related hyperkyphosis, independent of spinal osteoporosis, is associated with impaired mobility in older community-dwelling women. Osteoporos Int. 2011; 22:85-90.

36. Callisaya ML, Blizzard L, Schmidt MD, McGinley JL, Srikanth VK. Ageing and gait variability - a population-based study of older people. Age Ageing. 2010;39:191-197.

37. Forrest KY, Zmuda JM, Cauley JA. Patterns and determinants of muscle strength change with aging in older men. Aging Male. 2005;8: $151-156$.

38. Granacher U, Lacroix A, Muehlbauer T, Roettger K, Gollhofer A. Effects of core instability strength training on trunk muscle strength, spinal mobility, dynamic balance and functional mobility in older adults. Gerontology. 2013;59:105-113.

39. Zagozdzon P, Kolarzyk E, Marcinkowski JT. Quality of life and rural place of residence in Polish women - population based study. Ann Agric Environ Med. 2011;18:429-432.
Clinical Interventions in Aging

\section{Publish your work in this journal}

Clinical Interventions in Aging is an international, peer-reviewed journal focusing on evidence-based reports on the value or lack thereof of treatments intended to prevent or delay the onset of maladaptive correlates of aging in human beings. This journal is indexed on PubMed Central, MedLine,

\section{Dovepress}

CAS, Scopus and the Elsevier Bibliographic databases. The manuscript management system is completely online and includes a very quick and fair peer-review system, which is all easy to use. Visit http://www.dovepress. com/testimonials.php to read real quotes from published authors. 